\title{
Gönüllü̈lük, Katılım ve Yönetim Kültürü İlişkisi
}

\author{
DOI: 10.26466/opus.658674 \\ $*$ \\ Vasfiye Celik * \\ * Dr. Öğretim Üyesi, Kırıkkale Üniversitesi, İ̈BF, Kırıkkale/Türkiye \\ E-Posta: vasfiyezeynep@hotmail.com ORCID: 0000-0002-2176-892X
}

Öz

Bireylerin herhangi bir karşıllk beklemeden kamu yararım gerçekleştirmek amacıyla ve duyacakları manevi hazla hareket etmeleri gönüllülük kavramıyla açıklanırken gönüllü profili için yaş, cinsiyet, bağlı bulunan din veya mezhep, medeni ve ekonomik durum gibi değişkenler üzerinden konu analiz edilmeye çalışllmaktadır. Bu analizde, üyelikle gönüllü̈lüğ̈̈̈n birbirinden farklı değerlendirilmesi gerektiği özellikle belirtilirken bu profilde en çok üzerinde durulan konu, din ve mezhep değişkeni olmaktadır. Gönüllülü̈̆̆̈̈n dini yapılar üzerinden yapılmasının diğer ağlarla ilişikler için bir kapı araladığı dile getirilmekle birlikte bu konuda yapılan araştırmalar, tek bir sonuca ulaşmaktan ziyade farklllık arz etmektedir. Demokrasinin vazgeçilmez unsuru olan katılım kavramı ise gönüllülük ile birlikte modern toplumlarda hizmetlerin daha iyi gerçekleştirilmesi ve vatandaşların yönetim sürecine daha fazla katılması amacıyla son zamanlarda yan yana telaffuz edilmeye başlanmıştır. Ancak bu iki kavramın birlikteliği sivil toplum düşüncesine ve yönetim kültürüne bağh olarak ülkelerde farkl şekillerde kendine yer bulmaktadır. Konuya Türkiye açısından bakıldı̆̆ında ise net bir gönüllülü̈k tanımının olmaması, sivil toplum düşüncesindeki beklenen gelişmenin yokluğu ve katılımın resmi metinlerde kalması gönüllülük-katılım-yönetim kültürü ilişkisini kısaca açıklamaktadır.

Anahtar Kelimeler: Gönüllülük, Katılım, Yönetim Kültürü, Türkiye 


\title{
The Relationship between Volunteering, Participation and Administration Culture
}

\begin{abstract}
The concept of volunteerism explains that individuals act with their spiritual pleasure in order to realize the public benefit without expecting any provision, and so this analysis is carried out by such variables as age, gender, religion or sect affiliated, marital and economic status for the profile of volunteering. In this analysis, while it is stated that membership and volunteering should be evaluated differently, the most emphasized issue in this profile is the variable of religion and sect. Although it is stated that volunteering through religious structures opens a door for relations with other networks, the researches on this issue differ rather than reaching a single conclusion. On the other hand, the concept of participation, which is an indispensable element of democracy, has recently begun to be stated side by side with the aim of better service delivery in modern societies and citizens' participation in the managerial process. However, the combination of these two concepts has the place in different ways in the countries where depend on the thought of civil society and managerial culture. When the issue is considered in terms of Turkey, the lack of a clear definition of volunteerism, the absence of the development expected in the thought of civil society, and the existence of participation in the official texts briefly explain the relationship of volunteerism-participation-managerial culture.
\end{abstract}

Keywords: Volunteering, Participation, Administration Culture, Turkey 


\section{Giriş}

Alexis de Tocqueville'in "Amerika'da Demokrasi" adlı eserinde gönüllü eylemin toplumsal yaşamda hangi gruplar tarafından gerçekleştirildiği üzerine çalışması bu konuya ilgiyi artırırken, bu kavramın kökenleri İskoç Aydınlanması'na kadar götürülmektedir. Temelde karşılık beklemeden resmi veya gayri resmi ilişkiler çerçevesinde gerçekleştirilen bir olgu, faaliyet olarak görülen gönüllülük, toplumsal yaşamda farklı kişisel özellikler nedeniyle çok çeşitli şekillerde değerlendirmeye tabi tutulmaktadır. Demokrasinin vazgeçilmez unsuru olarak görülen katılım kavramı ve süreci ise toplumu çoğunluğun zulmünden koruyan temel bir değer olarak görülmekte fakat farklı idari gelenek veya yönetim kültürleri, uygulamaları farklılaştırmaktadır. Gönüllülük-katılım-yönetim kültürü beraber değerlendirildiğinde ise gönüllü katılımın farklı yönetim kültürleri içinde çok fazla değişken tarafından etkilenerek ama temelde manevi değerlere gönderme yapılarak ve devlet tarafından da farklı nedenlerle desteklenerek gerçekleştirilmeye çalışıldı$\breve{g} 1$ kabul edilmektedir.

Gönüllülük, katılım ve yönetim kültürüne ilişkin yapılan çalışma ve araştırmalarda, gönüllülü̈k analizinde kişisel özelliklerden yaş, cinsiyet, medeni durum, sahip olunan çocuk sayısı, ekonomik durum gibi faktörler göze çarparken en dikkat çekici gönüllü katılım unsuru herhangi bir dine veya mezhebe bağlllık konusunda görülmüştür. Dindar olarak nitelendirilen kimselerin daha fazla katılım ve gönüllü eylem içerisinde olduğu gözlemlenirken, mezhepsel farklılığın da bu konuda önemli olduğu ileri sürülmüştür. Ama ulaşılan sonuçlar her zaman bu durumu doğrular nitelikte olmamıştır. Temsili demokraside yaşanan temsil krizi ise yerini yavaş yavaş katılımcı demokrasi fikrine bırakırken ve katılımcılık ön plana çıkarken her şeyi devletten beklemek yerine vatandaşların da hizmetlerin görülmesinde etkilerinin olması gönüllülükle katılım kavramını yan yana getirmeye başlamıştır. Ancak bu yan yana geliş, güçlü bir sivil topluma ihtiyaç duymaktadır ki her toplumun bu gelişmişliğe ve gereken kurumsal yapıya sahip olmadığı belirtilmesi gereken başka bir konudur.

Kıta Avrupası yönetim kültürü içerisinde değerlendirilen; hukukun üstünlüğü, bürokrasi ve devletin bölünmez bütünlüğü fikri gibi temel olgularla kamu yönetimi örgütlenmesini gerçekleştiren Türkiye'de, gönüllülük genellikle dini bir bakış açısıyla gerçekleştirilmektedir. Gönüllülü̈̆ün yol 
arkadaşı katılım konusunda ise dünyadaki genel düşünce, katılımın daha görünür olması için sivil toplum kuruluşlarının güçlü olması mantığında yatarken Türkiye'de sivil toplumun hali hazırda çok etkin olamaması bu kavramı ve buna ilişkin uygulamaları güçsüz bırakmaktadır. Çünkü Türkiye'deki genel düşünce, vatandaşların bazı süreçleri başlatmasından çok devletin her alana hakim olması ve her şeyi yapması gereği üzerinedir. Bu çalışmadaki amaç ise sivil toplumun da yetersizliği kabulü ile katılım yollarının çok etkin kullanılmadığı Türkiye' de, ileride yapılabilecek gönüllü katılıma ilişkin çalışmalarda yönetsel kültür farklılı̆̆ı bağlamında ülke örnekleri ve yabancı literatürde dikkat çeken amprik çalışmalardaki değişkenler üzerinden bir rehberlik sağlayabilmektir. Ayrıca çalışmadaki temel başlıklar ayrıntılı örnekler üzerinden açıklanarak, farklı bakış açıları geliştirilmesine imkan sağlanmaya çalışılmaktadır.

\section{Gönüllülük}

Gönüllülük, kültürel, sosyal ve ekonomik bir fenomen olarak toplumların nasıl örgütlendiklerinin, sosyal sorumluluklarının nasıl paylaştıııldı̆̆ının ve vatandaşlardan beklenen katılım-sorumluluk ilişkisine göre anlamlandırılan bir kavram olarak karşımıza çıkmaktadır (Erlinghagen ve Hank, 2005). Bireyler, gruplar ve dernekler/kuruluşlar arasındaki sosyal ilişkilerin ve etkileşimlerin kalıplarını içeren bir olgu olarak da değerlendirilebilen gönüllülük; gönüllü, bedelsiz ve kolektif olarak yönlendirilmiş doğası nedeniyle, atfedilen ve resmi olandan farklı, benzersiz bir sosyal bağ türünü temsil etmekte, bu bağlamda toplumu birbirine bağlayan önemli ve istisnai bir sosyal dayanışma biçimi olarak fedakarlık, merhamet, başkaları için endişe, cömertlik, sosyal sorumluluk ve topluluk ruhu gibi temel insani değerlerin birincil ifadesi olarak göze çarpmaktadır. Ancak gönüllülük, içinde bulunulan durum itibariyle zaman zaman anlamsal olarak farklılaşabilmektedir. Örneğin, bir topluluk kulübü toplantısında konuşan ve hiçbir ücret almayan bir profesörün yaptığı bu faaliyeti, bazıları gönüllü bir faaliyet, bazıları kamu hizmeti diğer bir grup ise üniversite profesörlerinden kamu tarafından beklenenlerin bir uzantısı olarak görmektedir (Hustinx, Cnaan ve Handy, 2010, s.410-417). Başka bir örnek olarak da bazı dinsel inançlar AIDS mağdurlarına yardım etmeyi teşvik ederken, bazı dinsel inançlar ise bunu caydırmaktadır. Ya da ABD'deki muhafazakâr dini mezhep mensupları, gönül- 
lü çalışmayı dini anlamda bir adanmışlık olarak görürken, liberaller için gönüllü çalışma kişisel gelişim olarak değerlendirilmektedir (Wilson, 2000, s.219). Bu nedenle, gönüllülükle ilgili yapılan araştırmalarda kimin gönüllü olduğu ve hangi faaliyetlerin insanların gönüllülük inşası hakkındaki farklı anlayışlarına ilişkin bilgiler taşıdığı, kavram üzerinde netlik sağlanmasını zorlaştırmaktadır. Aslında bu durumun asıl nedeni, açıkça tanımlanamayan ve çok çeşitli faaliyetler, organizasyonlar ve sektörlere yayılan karmaşık bir olgu olarak gönüllülüğün bir halk algısı meselesi olmasında yatmaktadır (Hustinx vd., 2010, ss.410-417).

Gönüllülük kavramının kültürel kimlik ve toplulukla yakından bağlantılı olduğu aşikar olmakla birlikte gönüllü eylem düşüncesi en belirgin ifadesini Alexis de Tocqueville'in "Amerika'da Demokrasi" adlı çalışmasında bulmaktadır. De Tocqueville için gönüllü eylem ve gönüllü dernek, toplumu çoğunluğun zulmünden koruyan ve işleyen demokratik bir politikanın temel taşıdır. Günümüz şartları açısından değerlendirildiğinde kavram, kamu yararı için toplumsal hizmeti vurgulaması yanında büyük ve kâr amacı gütmeyen kuruluşlar ile de yakından ilgili olmaktadır. Bu konuda birçok ulusal ve uluslararası örgüt çalışmalar yürütürken bu kurumlardan biri olan Birleşmiş Milletler Örgütü gönüllüğü, bireylerin komşularının refahı ve genel olarak toplum için kâr amacı gütmeyen, maaşsız ve kariyer dışı eylem olarak yaptıkları katkılar olarak değerlendirmektedir (Anheier ve Salamon, 1999, s.48).

İnsanlara, gruplara veya örgütlere fayda sağlayan, kurumsallaşmış, ücretsiz yardımlaşma şekli olarak gönüllülük, finansal bir kazanç sağlamadığı için bu konuda insanların motive edilmesi anlamında farklı araçlara ihtiyaç duyulmaktadır. İnsanların "neden" gönüllü olduklarını anlamak için aranan cevap ise farklı şekillerde verilmektedir; (1) özgecil normlar, (2) sosyal ağlar (3) bilgi ve beceriler. Başkalarına yardım etmenin içsel motivasyonunu daha fazla hissetmek, dayanışma, insanlara duyulan sevgi ve fedakârlık önemli erdemlerdir ve bu özgecil normlar özellikle ibadet yerlerinde baskın bir şekilde verilmektedir. Bu da gönüllü olma şansının/durumunun artmasına neden olmaktadır. İkinci cevap olan sosyal ağ açıklamasına göre ise bir ibadet yerinin üyeleri daha fazla gönüllü olurlar, çünkü sosyal ağlar güçlü bir destek ve motivasyon sağlamaktadır. Yakın toplulukların bir parçası olan üyelerin, mevcut gönüllü kuruluşlar hakkında bilgi sahibi olma olasılıkları daha yüksektir. Bu da katılım talep etme şansını artırmaktadır ve 
ayrıca sıkı sıkıya bağlı olunan topluluk açısından bu tür istekleri reddetmeyi de zorlaştırmaktadır. Zira "resmi gönüllülerin çoğunun aile üyeleri, iş arkadaşları veya ibadet eden kişiler tarafından gönüllü olmaya ikna edildiğini" iddia ettikleri zaman, bu ağ açıklamasına atıfta bulunulduğu, dinden ziyade sosyal ağların gönüllü̈lüğe hâkim olduğu düşünülmektedir (Ruiter ve De Graaf, 2006, s.193).

Gönüllügün "nasıl" daha fazla olacağı konusunda ise iki görüss bulunmaktadır. İlki "normativist" model olup burada değerlerin, normların ve tutumların insan davranışı üzerindeki rolü vurgulanmaktadır ve bu anlayışta, bir davranışa yönelik olumlu tutumun birey üzerinde olumlu bir etkide bulunacağ 1 kabul edilmektedir. "Sosyal uygulama" modelinde ise gönüllülük, değer kalıpları ve normatif sistemler gibi nesnel sosyal yapıların sonucu değildir. Gönüllülük bir yatkınlıktır, insanlar günlük faaliyetler, uygulamalar vasıtasıyla belli davranış biçimlerine alışırlar. Bu uygulamalar sayesinde, insanlar sosyal rutinlere ve durumlara alışmakta ve rahatlamaktadır. Ancak konuya bu açıdan yaklaşıldığında sosyal uygulama perspektifinin, değerlerin ve tutumların rolünü küçümsediği ve bunun yerine uygulamanın bağlayıcı rolünü vurguladığı görülmektedir. Bu teoriye göre, insanlar gönüllülüğün "alışkanlığını" kazanırlar, çünkü rutin olarak gönüllü çalışma için düzenlenen sosyal beceri ve düzenlemelerin geliştirildiği sosyal durumlara ve sosyal ilişkilere yerleştirilirler. Bunun anlamı ise insanların işe başlamadan önce gönüllülük hakkında herhangi bir bilgiyi veya çekiciliği geliştirmelerine gerek olmamasına rağmen, olumlu (veya olumsuz) tutumlar başladıktan sonra bunu geliştirebilecek olmalarıdır (Janoski, Musick ve Wilson, 1998,s.495-498).

Nasıl daha fazla gönüllü olunur konusuna ilişkin farklı görüşler varken gönüllükk, yapılış şekline göre resmi ve gayri resmi şekillerde gerçekleştirilmektedir. Resmi gönüllülük, örgütlerin veya kuruluşların faaliyetlerine karşılıksız olarak katkı olarak tanımlanırken, gayrı resmi gönüllülük, örneğin bir komşuya veya arkadaşa yardım etmek gibi, hane halkı olmayan kişilere doğrudan ve resmi bir kuruluş aracıllğı olmadan gerçekleşen bir yardımdır ve bir dizi etnik grup ve toplulukta gayrı resmi gönüllülük, genellikle daha baskın bir yardımlaşma şeklidir. Bunun nedeni ise her ne kadar resmi ve gayri resmi gönüllülük birbirleri ile pozitif ilişkili olsa da farklı kişisel kaynaklar tarafından şekillendirilmesinde aranmaktadır. Şöyle ki sosyal ağlara katılım, her iki tür gönüllülük olasılığını arttırmakta ancak 
insan sermayesi sadece resmi gönüllülük olasılığını pozitif yönde etkilemektedir (Lee ve Brudney, 2012, s.159). Bu bilgiye karşın, başarılı uygulamalar görmek adına resmi gönüllük sürecine örnekler üzerinden bakılırsa, "Fortune 500 şirketleri"nin yüzde 90'ından fazlası, çalışanları için gönüllülük programları yürütmekte, çalışanların topluma hizmet verme çabalarını ve sosyal yardım faaliyetlerini resmi olarak desteklemektedir. Zira örgütler mola vererek, programlarını ve kaynak kullanımını değiştirerek gönüllü çabaları desteklediğinde, bir çalışanın yılda \% 45 daha fazla gönüllü çalıştığ görülmüştür. Bu süreci desteklemek adına Birleşik Krallıkta, eski Başbakanlar kurumsal gönüllülük programlarına desteklerini dile getirmiş ve 2000 yılında Tony Blair, işverenleri, gönüllü olmak için yılda bir gün çalışanlara izin vermeye teşvik etmiştir; Gordon Brown ise 2006'da "ülkemizin öncülügünü yapma ve her işverenin çalışanları için gönüllü bir programa sahip olduğu günü başaran ilk kişi olma vizyonunu" ortaya atmıştır (Grant, 2012, s.589). Aslında bu söylemlerin temelinde bu gibi faaliyetler sonucunda yani gönüllülerin hizmet sunumuna katılmaları ile devlet verimliliğinin artması ve devlet için maliyet tasarrufu beklenmekte, gönüllüler olmasa sunulamayacak hizmetler sunulabilmekte, acil durumlarda yardım sağlanmakta, mevcut kaynaklarla sunulabilecek faaliyetlerin ve devlet hizmetlerinin kalitesi artmakta, halk bilinçlenmekte ve halkın iş becerilerinin artması hedeflenmektedir. Avantajlar kulağa hoş gelmekle birlikte maalesef yaşanabilecek dezavantajlar da bulunmaktadır. Bunlardan ilki, bir gönüllü programı yürütmek için gerekli olan destek yapısının ciddi bir harcama gerektirmesi ve bu maliyetin karşılanmasının problem oluşturabilmektedir. Maddi desteğin yokluğu yanında gönüllülerin resmi kurum veya çalışanlar tarafından yeterli desteği alamamaları ise sonucu başarısızlı̆̆a götürebilmektedir (Brudney, 1993, s.285).

Gönüllülük kavramının ardından "gönüllü kimdir" sorusuna cevap bulunmaya çalışılırsa gönüllüler; gönüllü olarak yerine getirdikleri role, görev tasarımına ve zaman taahhüdü konusundaki beklentilerine göre farklı gruplara ayrılmaktadır. Geleneksek gönüllüler, uzun vadeli örgütsel bir bağlılık sergilemekte ve daha geniş bir topluluğa hizmet etmektedir. Yansitıcı gönüllüler ise kişisel ilgi alanlarına göre kendilerine bir alan belirlemekte ve çok daha rahat bir şekilde farklı projelerde yer alabilmektedirler. Aralıklı gönüllülük kısa süreli ve genellikle bir kerelik fırsatlara katılmak isteyenleri cezp ederken, ekonomik olarak yoksun bir alanda çocuklara hizmet veren 
diş hekimleri gibi etkinlik gönüllüleri de bulunmaktadır (McAllum, 2017, s.5). Ancak gönüllüleri ve gönüllüğü tanımlamak zor bir iştir ve mevcut tanımlar genellikle gönüllülügün "ne olmadığını" detaylandırmaya odaklanmaktadır. Bu konuya daha yakından bakılacak olursa:

Tablo 1. Gönüllülük Çerçevesi

\begin{tabular}{|c|c|c|}
\hline Karmaşıklık Katmanları & Teorik Yapıtaşları & Anahtar Çerçeveler ve Yaklaşımlar \\
\hline Tanım Problemi & Ne Çalışıyoruz? & $\begin{array}{l}\text {-Gönüllülüğün ne olmadığı } \\
\text {-Gönüllülüğün ne olduğu } \\
\text {-Sosyal bir yapı olarak gönüllülük }\end{array}$ \\
\hline Multidisiplinerlik sorunu & $\begin{array}{l}\text { Neden onun üzerinde } \\
\text { çalışıyoruz? }\end{array}$ & $\begin{array}{l}\text {-Ekonomistler: özgeciliği saflaştırmak } \\
\text {-Sosyologlar: sosyal uyum ve sosyal refah } \\
\text {-Psikologlar: prososyal kişilik } \\
\text {-Siyaset bilimciler: vatandaşlık ve demokrasi }\end{array}$ \\
\hline \multirow[t]{3}{*}{$\begin{array}{l}\text { Çok boyutlu olarak teori } \\
\text { sorunu }\end{array}$} & $\begin{array}{l}\text { Açıklama: } \\
\text {-Neden insanlar } \\
\text { gönüllü oluyor? } \\
\text {-Gönüllülük faktörleri }\end{array}$ & $\begin{array}{l}\text { Motivasyonlar ve faydalar: } \\
\text {-Dominant durum modeli } \\
\text {-Kaynak modeli } \\
\text {-Gönüllülükte uluslararası çeşitlilik teorileri }\end{array}$ \\
\hline & $\begin{array}{l}\text { Bir anlatı olarak teori: } \\
\text {-İnsanlar nasıl } \\
\text { gönüllü çalışır? } \\
\text {-Gönüllülük durumu } \\
\text {-Gönüllüllük ve sosyal } \\
\text { değişim }\end{array}$ & $\begin{array}{l}\text {-Gönüllülük tarzları } \\
\text {-Gönüllü süreci } \\
\text {-Gönüllü ekoloji } \\
\text { Gönüllü yönetim } \\
\text {-Gönüllülüğün değişen kurumsal ve biyog- } \\
\text { rafik yerleşimi }\end{array}$ \\
\hline & $\begin{array}{l}\text { Aydınlanma teorisi: } \\
\text { Eleştirel yaklaşım }\end{array}$ & $\begin{array}{l}\text {-Sosyal eşitsizlik sorunu } \\
\text {-Gönüllülü̈̆̆ün olumsuz sonuçları } \\
\text {-Karşılıklı beklentiler } \\
\text {-Gizli ideolojiler }\end{array}$ \\
\hline
\end{tabular}

Kaynak: (Hustinx vd., 2010, s.413).

Gönüllülük bu kavrama hangi açıdan bakıldığına bağlı olarak farklı bir şekilde, ama temelde herhangi bir karşılık beklemeden yapılan bir faaliyet olmakla birlikte, insan ve örgütlere pozitif etkisinden dolayı katılım sürecinin daha aktif hale getirilmesiyle toplumsal yaşamda daha fazla yer alması gereken bir olgu olarak değerlendirilmektedir.

\section{Katılım}

Katılım kavramı, en kısa şekliyle "halkı ya da temsilcilerini idari karar alma sürecine dâhil etmek için kurgulanan çeşitli mekanizmalardan herhangi biri" olarak tanımlanmaktadır. Önem arzetme konusunda sürecin meşrulaştırılmasını, demokrasinin güçlendirilmesini ve vatandaşlık kavramının içe- 
riğinin genişlemesini sağlayan bu kavram, farklı paydaş bakış açılarının dikkate alınmasını sağlayarak şeffaflık getirmekte, karar vericilerin daha hesap verebilir hale gelmesini sağlayarak da oy birliğine varma olasılığını artırmaktadır (Higgs, Berry, Kidner ve Langford, 2008, s.596). Dolayısıyla demokrasi tartışmalarının yoğun bir şekilde yaşandığı günümüz koşullarında katılım kavramının yaşanan problemleri azaltması ve üzerinde fazlasıyla durulan şeffalık, hesap verebilirlik gibi kavramların uygulanabilirliğini artırması beklenmektedir.

Uygulamada sonuçlar tartışılmakla birlikte teoride yönetilenlerin yönetim sürecine katılımı, neredeyse herkes tarafından alkışlanan ve saygın bir fikir olan demokrasinin temel taşıdır. Çünkü bu kavram sayesinde siyasi ve ekonomik süreçlerin dışında kalan vatandaş, geleceği şekillendirecek gücü yeniden dağıtmaktadır. Ancak bu süreçte katılımın boş ritüeli ortaya çıkabilmekte, sürecin sonucunu etkilemek için gereken gerçek güce sahip olupolmamak arasındaki ince çizgi, fark dikkate alınmalıdır. Bu farklılık çerçevesinde vatandaşların sonucu belirlemesindeki gücüne karşılık olarak, sekiz basamaktan bahsedilmektedir. Manipülasyon ilk, terapi ikinci basamağı oluştururken bu basamaklarda katılım, güç sahiplerinin katılımcıları eğitmelerini ve iyileştirmelerini kapsamaktadır. Üçüncü basamak bilgilendirme ve dördüncü basamak danışma olup bu seviyelerde katılımcı, sürecin nasıl işlediğini bilmemekte ama anlamlı veya kayda değer olup olmadığını tartışmakta ve konuşabilmektedir. Bu koşullar altında, vatandaş görüşlerinin güçlü olan tarafından dikkate alınacağını garanti etme gücünden yoksundur, dolayısıyla statükoyu değiştirme güvenceleri yoktur. Beşinci basamak olan teskin etmekde tavsiyede bulunulması söz konusu değilken, güçlülerin karar verme hakkı saklı tutulmaktadır. Altıncı basamakta vatandaşlar güç sahipleriyle pazarlık yapabilmekte, yedinci basamak olan temsil edilen güçte ise katılım artarak devam etmektedir. Sekizinci basamak ise vatandaş kontrolü adını almakta ama ismiyle tezat bir şekilde vatandaşlar tam bir kontrole sahip olamamaktadır. Konuya açıklık getirme anlamında bu sekiz basamak yardımcı olmakla birlikte her basamak her durumda kesin olarak belirmemekte, bazen katılıma ilişkin daha fazla basamakla da karşılaşılmaktadır (Arnstein, 1969, s.216). Arnstein'a göre, merdivenin daha işler hale gelmesi, bilgi ve iletişim teknolojilerindeki olumlu değişikliğe bağlı olarak değişmekte ve teknolojideki olumlu değişiklik katılıma olumlu etkide bulunmaktadır. Ancak bu olumlu etkiye rağmen bilgi sahibi olmayan insanlar 
için iletişim teknolojilerinden faydalanmak, katılımda tek yönlü bir bilgi aktarımı şeklinde gerçekleşmekte, konunun farkında olan, fakat yeterli teknik bilgisi olmayan insanlar için ekstra bir çabaya ihtiyaç duyulmaktadır (Hansen ve Reinau, 2006, s.29).

Katılım hem siyasal hem de yönetsel açıdan gerçekleşirken siyasi katılım, vatandaşların siyaseti etkileyen faaliyetleri olarak tanımlanabilmektedir. Ancak bu kısa tanıma rağmen siyasi katılım örneklerinin listesi neredeyse sınırsızdır. Bir benzetme ile ifade edilecek olursa birinin yapabileceği şeyleri ifade eden "repertuar" teriminde olduğu gibi bir siyasi katılım repertuarı, siyaseti etkileyen mevcut tüm faaliyetleri kapsamaktadır (Van Deth, 2014, s.351). Siyasi katılım kavramı tarihsel olarak incelendiğinde 1940 ve 50'li yıllarda oy kullanma ve kampanya faaliyetleriyle sınırlanmış, 60'lı yılların başında politikacıların ve partilerin kampanyası olarak geleneksel siyaset kavramsallaştırmaları ile ilgili faaliyetler ve vatandaşlar ile kamu görevlileri arasında iyi kabul gören temaslar olarak görülmüştür. 60'ların sonu ile 70 'lerde ise topluluk gruplarını artan ilgisi yanında vatandaşlar, kamu görevlileri ve politikacılar arasındaki doğrudan temas nedeniyle geleneksel siyasi katılım biçimleri genişletilmiştir ve 70'lerdeki protestolar, kadınlar veya yeni pasifist örgütlerin faaliyetleri alışılmadık katılım biçimleri olarak görülmüştür. 90'lı yıllarda politik olan ve olmayan arasındaki sınırın belirsizleşmesi yanında, gönüllülük ve sosyal katılım gibi kavramları bünyesine katarak genişlemiştir. Modern toplumlardaki vatandaşların doğrudan ve aktif katılımı güçlü demokrasinin benzersiz bir belirtisi olmakla birlikte siyasal katılım eksikliği demokrasi için yıkıcı bir unsur olarak kabul edilmektedir. Buna ilişkin tartışmalar ise katılımın gerekliliği üzerine değil, katılımın derecesine göre yapılmaktadır (Van Deth, 2001).

Kavrama yönetsel açıdan bakıldığında siyasal ve yönetsel kadroların belirlenmesinden çok, onların almış olduğu kararlara, yapmış oldukları işlemlere vatandaşların ve sivil toplum kurumlarının katılımı anlaşılmaktadır. $\mathrm{Bu}$ katılım şekli; kent konseyleri başta olmak üzere halk oylaması, halk toplantıları, geri çağırma, yurttaş kurulları, iletişim demokrasisi (internet), kamuoyu yoklaması, yuvarlak masa toplantıları, gelecek atölyeleri, belediye meclisi toplantılarına katılma, danışma kurulları, telefon, dilekçe, çeşitli forumlar, sivil toplum kuruluşları, planlama çemberleri gibi farklı şekillerde gerçekleştirilmeye çalışılmaktadır (Kestellioğlu, 2011, s.125) ki bu yollarla sürece 
katılım, yerelden başlayarak gönüllü bir şekilde gerçekleştirilirse alınan kararların etkinliğinin daha artacağ 1 beklenmektedir.

Günümüzde fazlasıyla üzerinde durulan bir kavram olarak katılımın aynı zamanda çok tartışılmasının altında ise "temsili demokrasi"ye yönelik eleştiriler yatmaktadır. Çünkü son dönemlerde temsili demokrasinin sadece temsili öne çıkaran demokratik siyaset tarzının, artık sürdürülebilir olmaktan uzak olduğu düşünülmektedir. Temsili demokrasinin, toplumların yönetim sorunlarına çözümler üretmede yetersiz kalması, hatta "kriz" içinde olduğunun düşünülmesi karşısında katılımın, özelde ise yerel katılımın genişletilmesi gerektiği ileri sürülmektedir. Halkın katılımının belli periyotlarla sinurlanması, bunu takiben siyasetin, yönetimin yozlaşarak halka yabancılaştığına inanılan temsili demokrasideki bu olumsuzluklar, oy hakkına sahip olan kesimlerin kapsamını genişletmek ve bu bağlamda kamusal işlerle ilgili karar verme sürecine katılımı arttırıp yaygın hale getirmek niyetindeki katılımcı demokrasi ile gerçekleştirilebilecektir (Önder, 2013, s.312). Uygulamada, kamu sektörünün daha etkin işleyebilmesi için devletin faaliyetlerinde katılımc bir anlayışın benimsenmesi, hizmet sunduğu alanlarda rekabetçi piyasa yapısından yararlanılması ve önceliklerin belirlenmesinde toplumun taleplerine daha fazla kulak veren katılımcı mekanizmaların oluşturulması ile temsili demokrasi yerini katılımc demokrasiye bırakmaktadır (Yalçın, 2015, s.313). Bu anlayışa geçilmesine neden olan temel problem, demokrasi tipinin uygulanabilirliğinde olup halkın katılımı sorunu, 60'lı yılların sonlarına ve 70'li yılların başlarına kadar uzanmaktadır. Çünkü bu halk katılım biçimi, çeşitli "uzmanlar" ve "karar vericiler" in kararlarına göre gerçekleştirilmiştir ve yetkililer ile vatandaşlar arasındaki gerçek bir etkileşim ise oldukça sınırlı kalmıştır (Hansen ve Reinau, 2006, s.25).

Bu konuyu, aslında problemi açıklamak adına şu ana kadar ikna edici bir şekilde kavramsallaştırılamayan "davet edilen katılım" terimini kullanmak oldukça doğru bir tercih olmaktadır. Bu katılım terimi, ilgili vatandaşlar tarafından değil dışarıdan başlatılan ve organize edilen bir halk katılım biçimi anlamına gelmekte ve çatısmaları önlemek için neo-liberal bir yönetim aracı olarak görülmektedir. Bu katılım şekli "aşağıdan" gerçek talepleri ifade eden bir protesto olarak değil, sık sık bir araştırma projesi olarak kurulan ve başından sonuna kadar mevcut olan araştırmacılar ekibi tarafından gözlemlenen bir deney olarak gerçekleştirilmektedir. Bu durum "laboratuar olarak toplum" veya "gerçek hayat deneyleri" gibi terimlerle sosyolojik 
olarak son dönemde tartışılmaya çalışılmaktadır. Zira toplum genel olarak bilginin üretildiği bir laboratuar haline gelirken, halkın katılımı toplumdan laboratuara geri çekilmektedir (Bogner, 2012, s.507, 521).

Laboratuar olarak toplumdan uzaklaşmak ve katılımcı demokrasiye hayat vermek için sivil toplum ve kuruluşlarının geliştirilmesi gereği elzem bir durum olarak görülmektedir. Demokratik bir devlete gönderme yapılarak, “Toplumsal sorunlara etkili ve uzun-dönemli çözüm bulma sürecine aktif olarak katılan ve bu temelde de siyasi aktörleri bu çözümleri yaşama geçirecek politikalar üretmeye yönlendirmek için çalışan farklı gönüllü örgütlerin devlet denetimi dışında kurduğu ortak alan" olarak tanımlanan sivil toplum (Keyman, 2017,s.3), demokrasi, çoğulculuk, hukukun üstünlüğü, katılımcillk, bireyin özgürleşmesi ve siyasi sürece yön verebilmesi gibi kavram ve düşüncelerle özdeşleştirilmektedir. Konumuz açısından değerlendirildiğinde ise gönüllü katılım, genellikle sivil toplum kuruluşları vasıtasıyla sağlanmakta, ancak yönetsel kültür, gönüllülük ve katılım konusunda farklilıklara neden olabilmektedir.

\section{Yönetim Kültürü}

Gelenek, sosyalleşme sürecinde kavranan ve toplanan bir inanç dizisidir ve şarta bağll, sürekli gelişim içinde, zorunlu olarak tarihsel bir bağlamda ve teorilerden ve anlatılardan oluşmaktadır. Devlet geleneği (yönetsel kültür) ise kurumlar ve devlet tarihi hakkında kalıtsal bir inanç kümesi olarak değerlendirilmektedir (Rhodes, 1999,s.352) ve burada kamu yönetiminin niteliğini tanımlayan, normatif kurumsallaşmanın az da olsa bir kısmını temsil eden tarihsel temelli değerler, yapılar ve diğer kurumlarla ilişkiler belirtilmektedir. Her ülkenin kendi geleneğine dair kendi yorumu olmakla birlikte bu gelenekler birkaç başlıkta gruplandırılmakta ve bu kalıplar kamu yönetimini anlama ve yorumlamada aracilik etmektedir (Peters, 2008, s.118).

Bu kalıplar dikkate alındığında iki farklı devlet anlayışı yanında dört farklı kamu yönetimi tarzından bahsedilmektedir. Devlet anlayışı farklıığında ilki, devletin ulusa aktif müdahale ve kontrol ile önderlik etmek için toplum üzerinde özerk otorite yapıları geliştirdiği “devlet liderliğindeki toplum"dur ki bunun örneği Fransa'dır. İkincisi ise "toplum liderliğindeki devlet"tir ve örneği İngiltere olup, devletin yerine ulusal meşruiyeti olan kurumlardan oluşan bir ağ bulunmaktadır. İkinci modelde, siyasi etki dev- 
letin zorunlu müdahalesi üzerine değil, toplumsal değerler üzerine kuruludur. Bu farklılıklar ise farklı hukuk anlayışlarına neden olmuştur. Kıta Avrupası devletlerinde devlet ve toplumun ayrılması, topluma idari müdahaleyi güçlendirmek için ayrıntıll, usule ilişkin ve temel hükümler içeren kapsamlı bir idari hukuk sisteminin geliştirilmesiyle ortaya çıkmaktadır. Bu nedenle, idari işlem temel olarak olası eylem planlarını tanımlayan yasal kurallarla ilgilidir. Öte yandan, yukarıda örnek olarak verilen İngiltere'de ise idare hukuku ve hukuki teftiş nispeten daha az gelişmiştir ve resmi yasal kurallar idari faaliyetler için Avrupa kıtasında olduğundan daha az önemlidir (Knill, 1998, s.9).

Günümüzde dünyada önemli kabul edilen Anglo-Sakson (devlet içermeyen), Alman (organik), Fransiz (Napolyoncu) ve İskandinav (AlmanAnglo-Sakson karışımı) kamu yönetimi tarzına daha ayrıntılı bakılacak olursa;

Tablo 2. Yönetim Kültürü Sınıflandırması

\begin{tabular}{|c|c|c|c|c|}
\hline & Anglo-Sakson & Alman & Frans1z & İskandinav \\
\hline $\begin{array}{l}\text { Devletin Hukuksal } \\
\text { Kavranışı }\end{array}$ & Yok & Evet & Evet & Evet \\
\hline $\begin{array}{l}\text { Devlet-Toplum } \\
\text { Illişkileri }\end{array}$ & Çoğulcu & Organik & Çelişik & Organik \\
\hline $\begin{array}{l}\text { Siyasal } \\
\text { Örgütlenme } \\
\text { Biçimi }\end{array}$ & $\begin{array}{l}\text { Sinırlı } \\
\text { Federalist }\end{array}$ & $\begin{array}{l}\text { Bütüncül- } \\
\text { organik } \\
\text { Federalist }\end{array}$ & $\begin{array}{l}\text { Jakoben, } \\
\text { Bölünmez bütün }\end{array}$ & $\begin{array}{l}\text { Yerelleşmiş } \\
\text { bütün }\end{array}$ \\
\hline Politika Tarzı & Değişken & $\begin{array}{l}\text { Elyordamı, } \\
\text { Yasal }\end{array}$ & Korporatist, Yasal & $\begin{array}{l}\text { Teknokratik, } \\
\text { Uzlaşıcı }\end{array}$ \\
\hline $\begin{array}{l}\text { Yerelleşme } \\
\text { Biçimi }\end{array}$ & $\begin{array}{l}\text { Devlet iktidarının } \\
\text { yerelleşmesi-ABD } \\
\text { Yerel } \\
\text { yönetim-İngiltere }\end{array}$ & $\begin{array}{l}\text { İşbirlikçi } \\
\text { Federalizm }\end{array}$ & $\begin{array}{l}\text { Bölgeselleşmiş } \\
\text { tekçi devlet }\end{array}$ & $\begin{array}{l}\text { Güçlü yerel } \\
\text { özerklik }\end{array}$ \\
\hline $\begin{array}{l}\text { Kamu Yönetimi } \\
\text { Disiplinindeki } \\
\text { Egemen } \\
\text { Anlayış }\end{array}$ & $\begin{array}{l}\text { Siyaset } \\
\text { bilim-Toplumbilim }\end{array}$ & $\begin{array}{l}\text { Kamu } \\
\text { Hukuku }\end{array}$ & $\begin{array}{l}\text { Kamu } \\
\text { Hukuku }\end{array}$ & $\begin{array}{l}\text { Kamu } \\
\text { Hukuku-İsveç } \\
\text { Örgüt } \\
\text { Teorisi- Norveç }\end{array}$ \\
\hline Ülkeler & $\begin{array}{l}\text { İngiltere, } \\
\text { ABD, Kanada } \\
\text { (Quebec dişında), } \\
\text { İlanda }\end{array}$ & $\begin{array}{l}\text { Almanya, } \\
\text { Avusturya, } \\
\text { Hollanda, } \\
\text { İspanya } \\
\text { (1978'den } \\
\text { sonra), Belçi- } \\
\text { ka (1988'den } \\
\text { sonra) }\end{array}$ & $\begin{array}{l}\text { Fransa, İtalya, } \\
\text { Portekiz, Quebec, } \\
\text { Yunanistan, } \\
\text { İspanya } \\
\text { (1978'e kadar), } \\
\text { Belçika } \\
\text { (1988'e kadar) }\end{array}$ & $\begin{array}{l}\text { İsveç, Norveç, } \\
\text { Danimarka }\end{array}$ \\
\hline
\end{tabular}

Kaynak: (Loughlin ve Peters, 1997, s.46). 
Bu geleneklerden Alman geleneğinde kamu hizmeti topluma değil, devlete ve hukuka karşı sorumludur, dolayısıyla idari şeffaflık bir zorunluluk değildir. Dahası hukukun üstünlüğü ilkesi, halkın idari karar alma sürecine katılması yerine, öznel bireysel hakların korunmasına vurgu yapmaktadır. En az resmi ve kodlanmış kısıtlamaya sahip ülke olan İngiltere'de ise kamu yönetimi organizasyonu kapsamlı bir hiyerarşik sisteme değil, zamanla kademeli olarak gelişen, gevşek bir şekilde birleştirilmiş bir sisteme veya özel otoritelere dayanmaktadır. Bu azaltılmış kurumsal genişlik seviyesi, idari yeniden yapılandırmayı kolaylaştırmaktadır. Fransa'daki idari düzenlemeler, yüksek derecede bir düzenleyici çeşitlilikle karakterize edilmektedir. Zira topluma yukarıdan müdahale ve rehberlik eden güçlü bir bürokrasi vardır. Bürokraside homojen, merkezileşmiş ve profesyonel elitlerin baskınlığı göz önüne alındığında, sektörel temel özelliklerde değişiklik yapılmasına izin veren ulusal reform dinamikleri için sınırlı bir alan kaldığı görülmektedir (Knill, 1998,s.18-30).

\section{Gönüllülük, Katılım ve Yönetim Kültürü İlişkisi}

Bir tür sosyal davranış biçimi olarak görülen gönüllülügün, katılım boyutuyla ve sivil toplum kuruluşları vasıtasıyla birlikte daha aktif hale gelmesi arzulanan bir durum olmakla birlikte, ülkelerin dâhil olduğu yönetim kültürü, devlet-toplum-vatandaş ilişkileri bağlamında konuya farklı yaklaşılmasına neden olmaktadır. Bu genel bir durum olmakla birlikte gönüllü katılım cinsiyete, yaşa, medeni duruma, eğitim seviyesine, çocuk sayısına veya dindar olup olmamaya göre de değişen bir durum olarak ülkelerde farklı şekillerde karşımıza çıkmaktadır.

Gönüllülük-katılım ilişkisinde, gönüllülük özel davranışların kamusal alana bir uzantısı olarak değerlendirildiğinde, gönüllü bir derneğin aktif katılımcısı olmayı gönüllülükten ayırmak gerekmektedir. Zira gönüllü bir derneğin aktif katılımcısı, kuruluşun sağladığı kolektif ürünleri tüketirken; gönüllü, bu ürünlerin üretilmesine yardımcı olmaktadır. Ayrıca sosyal aktivistler toplumsal değişime yönelirken; gönüllüler, bireysel sorunların iyileştirilmesine odaklanmaktadırlar. Kendilerini aktivist olarak görmeyen gönüllüler ise politika ile ilgilenmemekte, insanlara önem vermek öncelikleri olmaktadır (Wilson, 2000,s.216). Dolayısıyla gönüllü, katılımcı veya aktivist olma açısından da farklılıklar olduğu bilinerek açıklamalarda bulunmak 
gerekmektedir. Ayrıca aktif katılım ile gönüllülük anlayışını doğru değerlendirmek gerekmektedir ki, burada karşılaşılan problemlerden ilki, aktif katılım süreçlerine ilişkin basmakalıp yorumlar yerine tüm katılım biçimlerine ilişkin ampirik bilgilerin geliştirilmesi gereğidir. İkincisi ise farklı türdeki kurumların (kamu, özel ve kâr amacı gütmeyen) ayrı veya işbirliği içinde vatandaşların katılımını teşvik etmek ve mümkün kılmak için pratik olarak nasıl katkıda bulunduklarını anlamak ve anlatabilmektir (Boje, 2015,s.246).

\section{Gönüllï Katılımcı Profili}

Gönüllü katılıma ilk olarak kişisel ve özel durumlar açısından yaklaşıldığında, bir bireyin niteliklerinin ve sosyal bağlarının, gönüllü aktivitelere katılımını şekillendirdiği düşünülmektedir. Sosyal sermaye, hem resmi örgütler hem de gayri resmi sosyal ağlar da dâhil olmak üzere, insanların birbirleriyle sahip oldukları güven ağları ve ortak değerlerden oluşmaktadır ve gönüllülük kararının kısmen bir kişinin sosyal sermayesi tarafından şekillendiği öne sürülmektedir. Bu açıdan yaklaşıldığında sosyal sermaye, gönüllülü̈k olasılığını en az üç şekilde artırmaktadır. Birincisi gönüllülük, gönüllülügün faydalarının toplum üyeleri tarafından paylaşıldığı ve maliyetlerin bireysel gönüllüler tarafindan karşılandığı ortak malların üretimi ile sonuçlanmaktadır. Ekonomik davranışın fayda ve maliyetlerin hesaplanmasını içermesi koşuluyla, fayda artırıcı bir birey normalde gönüllülüğe katılmayı seçmeyecektir, çünkü katılım maliyetleri genellikle faydalardan ağır basmaktadır. Gönüllülüğün algılanan faydaları, sosyal ağlar aracılığıyla topluluğa daha fazla dâhil olan bireyler için daha büyük olduğundan bu kişilerin, daha az ağa sahip olanlardan daha fazla gönüllü olma olasıllğ bulunmaktadır. İkincisi gönüllülüğün "birinin emeğinden faydalanacak olanlarla bağlantı kurma hissi" olarak bir kimlik ifadesi olduğu düşüncesidir. Zira gönüllülük gibi bireysel davranışların ardındaki en güçlü nedenlerden biri olarak bir grupla özdeşleşmek, gönüllülüğe katılımda büyük rol oynamaktadır. Son olarak, sosyal sermaye gönüllülüğe katılımı arttırır. Şöyle ki bir bireyin sosyal bağları ne kadar fazlaysa, gönüllü olan insanlarla iletişim kurma olasılığı o kadar yüksektir ve sonuçta gönüllü olmanın istenmesi gönüllü olma olasılığını önemli ölçüde arttırmaktadır (Lee ve Brudney, 2012, s.162). 
Bu beklentinin ardından tipik gönüllü profili, eğitim ve gelirde ortalamanın üzerinde, ebeveyn ve kilisede aktif olan bir kimse olarak tarif edilmektedir. Ancak bu basmakalıp ifadelerin ötesinde, eğer insanlara gönüllülük erken yaşlarda öğretilirse ve vatandaşlara kendilerinden daha az şanslı olanlara yardım etmeleri noktasında vatandaşlık görevleri hatırlatılırsa, daha fazla gönüllü emek arzının olacağı düşünülmektedir. Bu düşüncede gençlerin gönüllülüğe erken yaşta dâhil edilmesinin önemi de ayrıca vurgulanmaktadır (Janoski vd.,1998, s.495-498). Ergenlik döneminde, toplumsal katılım yoluyla toplum yaşamına katkıda bulunmak, ergenlerin öz yeterliliklerini ve kişisel kontrollerini arttırmakta ve olumlu gelişimsel sonuçlar ortaya çıkarmaktadır. Ancak son 20 yılda birkaç ülkede yapılan tanımlayıcı çalışmaların sonuçları gençler arasında geleneksel politikaya karşı ilgisizliğin arttığını göstermiştir. Örnek verilecek olursa İtalya'da 18-26 yaşları arasindaki ulusal olarak temsili bir genç örneklemin sadece \% 3'ü aktif olarak politikaya dâhil olduğunu açıklamıştır (Cicognani, Pirini, Keyes, Joshanloo,Rostami, 2008, s. 97).

Yüksek sosyal ve ekonomik statüye sahip kişilerin daha fazla gönüllü olma eğilimi gösterdiği, "baskın statü modeli” olarak kavramsallaştırılmaktadır. Bu mekanizmada, gönüllülüğün yalnızca toplumda zengin, eğitimli ve iyi konumlanmış kişiler tarafından gerçekleştirildiği kabul edilmemekte, aynı zamanda sosyoekonomik durumları yüksek olanların gönüllülük oranlarının daha yüksek olduğu, birçok örgütün faaliyetlerinde daha prestijli ve anlamlı görevleri yerine getirme eğilimi gösterdiği de ifade edilmektedir (Hustinx vd., 2010, s.422). Diğer değişkenlerden orta yaş, gönüllülük için en ideal dönem olarak görülürken; cinsiyetçilik açısından konuya yaklaşıld1ğında, Kuzey Amerika'daki kadınların erkeklerden daha gönüllü olduğu, mevzu Avrupa olunca ülkeler arasında farklılık olduğu görülmektedir (Wilson, 2000, s.227). Birleşik Krallık ve Hollanda'da kadınlar ön plandayken, diğer Avrupa ülkelerinde durum tam tersidir hatta İsveç de gönüllü çalışma, erkek egemen bir şekilde gerçekleşmektedir (Boje, 2015, s.259). Irksal farklılığa bakıldığında ise düşük eğitim, gelir seviyesi ve mesleki statü durumu farklılaştırmaktadır (Wilson, 2000, s.227).

En önemli olgulardan biri olan din açısından konuya yaklaşıldığında ise yapılan araştırmalar genellikle Batı kökenli olduğundan, sonuçlar kiliseye bağlılık üzerinden değerlendirilmektedir. Ayrıca bazı araştırmalarda dini katılımın, diğer sivil katılım biçimlerine bir geçit olduğu iddia edilmiştir. 
Ancak bu nedenle ve vasıtayla katılımın yüksek olması halinde, kilise dışı örgütlerde gönüllü olma olasılığının azaldığı tespiti de yapılmıştır. Katılım seviyesinin ne kadar olacağı sorusu yanında, kiliseye ve diğer dini örgütlere katılımın, bireylere diğer alanlardaki gönüllü faaliyetleri teşvik eden sosyal ağları içeren sosyal sermayeye ulaşma araçları ve özel beceriler sağladığı da ileri sürülen başka bir argüman olmaktadır. Protestanların gönüllü katılımlarının, diğer mezhep ve dinlere nazaran özellikle Amerika'da daha fazla olması beklenirken, yapılan çalışmalarda farklı sonuçlara ulaşılmıştır. Bu farklılığa ilaveten bir kilise grubunun aktif üyelerinin daha fazla gönüllü olduğunu, ancak kiliseye katılımın kendisinin gönüllülük üzerinde anlamlı bir etkisinin olmadığı tespiti yapılmıştır. Çünkü dini katılım temelde gönüllülük üzerinde olumlu etkiye sahip olmakla birlikte bu katılım, gönüllü faaliyetlere göre değişmektedir (Lam, 2002, s.406).

Bütün bu tezler yanında ve her şeye rağmen kilise üyeleri, genellikle gönüllü kuruluşlara üye olmayanlardan daha fazla katılımcı olmaktadırlar. $\mathrm{Bu}$ sadece gönüllülerin üçte birinden fazlasının dini örgütlerde aktif olduğu Amerika için geçerli değildir. Daha seküler Avrupa toplumlarında bile dini örgütler en yaygın gönüllü kuruluşlar arasındadır. Ancak şu da belirtilmelidir ki gönüllülük kilise üyeliğinden değil, kiliseye katılım düzeyinden kaynaklanmaktadır (Ruiter ve De Graaf, 2006,s.191). Bu örneklere ek olarak gönüllü katılımın yüksek olduğu ülkelerin birçoğunda güçlü Protestan geleneği gözlemlenirken, bu durum her ülkede aynı olmayıp, gönüllü katılım konusunda en iyilerden Amerika, Kuzey İrlanda, İsveç ve Avustralya Protestan iken, gönüllü katılımın yine çok olduğu Kanada ve Belçika'da Katolik nüfusun daha fazla olduğu görülmektedir (Curtis, Grabb, Baer, 1992,s.149).

Gönüllü katılım-nüfus arasındaki ilişki değerlendirildiği zaman da gönüllü emek sunan nüfusun payı ülkeden ülkeye önemli ölçüde değişmektedir. İsveç, gönüllü işgücü sağlayan tüm yetişkinlerin \% 56'sının payı ile OECD üyesi ülkeler arasında en yüksek katılım oranını sergilerken, bunu Slovak Cumhuriyeti (\% 54), ABD (\% 50), Kanada (\% 48) ve Hollanda (\% 44) izlemektedir. \% 14 ile \% 16 arasında değişen, katılım oranının en düşük olduğu ülkeler ise Polonya, Japonya, İspanya ve Macaristan'dır (Hackl, Halla, Pruckner, 2012,s.466). 


\section{Gönüllü Katılım ve Sivil Toplum Kuruluşları (STK)}

Sivil toplum kuruluşları (STK) ile gönüllü katılım ilişkisinde, farklı örgütlü sivil toplum türleri ve farklı coğrafyalar dikkate alınarak konu analiz edilmelidir. Bunlardan ilki (burada yönetim kültürü çerçevesinde de bir değerlendirme yapılabilir) Güney Avrupa ülkelerini kapsar şekilde, İrlanda'nın da az çok içinde bulunduğu ancak genel olarak Fransa, İspanya ve İtalya örneğinde olduğu gibi, görece daha az STK üyeliği özelliği olsa da üyelerin yüksek düzeylerde gönüllü katılımda bulunduğu dar amaçlı (parochial) sivil toplum anlayışıdır. Bu ülkeler Katolik olması açısından benzerdirler. Bir diğeri ise aktif sivil toplum anlayışı olup, bu ülkeler de Kuzey Amerika ( $\mathrm{ABD}$, Kanada gibi) dadır ve buralarda hem üyelik hem de gönüllülük yüksek düzeydedir. Sonuncu ayrımda ise İskandinav ülkeleri örneğinde olduğu şekliyle, STK üyeliği yüksek düzeylerde olsa da üyelerin gönüllü katılım oranlarının görece düşük olduğu geniş amaçlı (broad) sivil toplum anlayışı karşımıza çıkmaktadır (Dekker ve Van Den Broek, 1998, s. 29).

Anglo Sakson çoğulcu geleneği, devletin temelinde olan doğal hukuktan ziyade bir sözleşmeye dayanarak devlet ile sivil toplum arasında belirgin bir sınır çizmektedir. Bu sınırda, İngiltere'de olduğu gibi devlet-sivil toplum ilişkisi sadakat ve uyum üzerinedir. Napolyon geleneğinde Fransız devleti, tek ve bölünmez bir cumhuriyet olarak görülmekte ve devlet ile sivil toplum arasında rekabet veya çekişme güçlü bir merkezi devlet tarafindan kullanılmaktadır. İskandinav geleneği ise anayasal devlet geleneğinden etkilenmekle birlikte, güçlü bir katılım etiğine sahip, merkezi olmayan bir üniter devlet olma konusundaki Germen geleneğinden farklılaşmaktadır. Karar alma sürecine katılım daha düzenli ve resmileştirilmiş bir halde olup devlet-sivil toplum ilişkisi katılım, kapsayıcı ağlar ve aktif vatandaş şeklinde analiz edilmektedir (Rhodes, 1999, s.353-359).

Konuya hangi açıdan bakılırsa bakılsın sivil katılım, yalnızca vatandaşların seslerini yükseltme ve halkla ilişkiler ile çıar görüşmelerinde yer alma anlamında değil, aynı zamanda refah hizmetleri sağlama konusunda aktif katılım olarak algılanmakta ve tartışılmaktadır. Bu nedenle sivil katılım ve gönüllülük, sivil toplum fikrine veya birey ile devlet arasındaki bağımsız örgütlenme katmanına bağlı görülmektedir (Boje, 2015, s.250). Şöyle ki insanlar hak talep edebilirler, bunu yapma yetkisine sahip olduklarında ve kendi gönüllü liderlik örgütlerini kurduklarında kendi yaşam kalitelerini 
zenginleştirmiş olurlar. Bu süreçte sivil toplum örgütlerine, topluluklara etkili bir şekilde yardım etmeleri ve vatandaşlar ile hükümetler ve şirketler gibi güçler arasında tampon oluşturmaları için ihtiyaç duyulmaktadır. Çünkü aktif gönüllü katılımın olmadığı bir toplum, totaliter ve baskıcı olma riski altındadır. Dolayısıyla gönüllü faaliyetler birçok vatandaşa, vatandaşlık becerileri edinmeleri ve siyasi katılımı teşvik etmeleri için firsat sağlamaktadir (Hustinx vd., 2010, s.419).

Sivil toplumun sistem nezdinde katılımınin olmaması durumunda, vatandaşlar karar alma firsatları bulunmayan alıcilar haline gelmektedirler. Etkili katılım sağlamak içinse vatandaşların taleplerini karar vericilere iletebilecekleri şekilde bilgilendirilmeleri gerekmektedir. Buradan hareketle, diyalog ve tüm aktörlerin karar vermesi üzerine odaklanan vatandaş katılımı, vatandaşın sözde kamusal alanın tüm yönlerinde aktif bir rol oynadığını veya vatandaşların bireysel veya toplu olarak birleştirilebileceği aşamalı bir süreç olarak tanımlanmasına neden olmaktadır (Bachmann, Delgado, Marin, 2007, s.253).

\section{Gönüllü Katılımda Devlet Örnekleri ve Yönetsel Kültür}

Gönüllü katılımda ulusal farklılıklar üzerine yapılan çalışmalar aynı sonuçlara ulaşmamakla birlikte, bu çalışmalarda dört faktör üzerinde durulmaktadır. İlk faktör ekonomik nedenlere odaklanırken, bir diğeri dini etkilere işaret etmekte, diğer ikisi ise politik faktörlere vurgu yapmaktadır. Ekonomik faktörde bir toplumun sanayileşmesi ne kadar erkense gönüllü katıllmın o kadar fazla olduğu görülmektedir. Bu argüman, sanayileşmenin mesleki uzmanlaşmaya, yükselen eğitim ve gelir seviyelerine yol açtı̆̆1 ve bu değişikliklerin toplumda sosyal statü farklılıklarını arttırdığı, bunun etrafında da çeşitli gönüllü çıkar gruplarının oluşacağı tezine dayanmaktadır. Din üzerinden yapılan çalışmalarda Protestanlık mezhebinin toplumsal ihtiyaçları karşılamak üzere devletten ziyade hayırseverlik kavramını ön plana çıkardığı ve dolayısıyla gönüllülüğü daha fazla desteklediği sonucuna ulaşılmaktadır. Nedeni ise Katolik kiliselerinin daha hiyerarşik ve elit, Protestan kiliselerinin daha eşitlikçi ve katılımcı olarak değerlendirilmesi olmaktadır. Siyasi yorumlara bakıldığında ise farklı siyasi örgütlenme türlerinin demokrasiler üzerindeki etkileriyle ilgilenilmiştir. Liberal, sosyal demokrat ve geleneksel korporatist demokrasiler, gönüllü derneklerin kurul- 
ması konusunda karşılaştırıldığında geleneksel korporatist demokrasilerin, liberal ve sosyal demokrasilerin gerisinde kaldığı iddia edilmiştir. Güçlü devlet mantığına ve varlığına rağmen sosyal demokrasiler, gönüllügün artmasını engellememektedir. Çünkü sosyal demokrasiler, toplumdaki hem sendika üyeliğinin hem de siyasi örgüt üyeliğinin genişlemesini kabul etmektedir. Son tahlilde ise demokrasi türüne odaklanmaktan ziyade, demokrasinin istikrar veya sürekliliğinin derecesinin, toplumun katılım düzeyini ve farklı toplumların örgütlenme katılımını etkileyen önemli bir faktör olduğu kabul edilerek değerlendirme yapılmaktadır. Bu bulgu, toplulukların diğerleriyle gönüllü olarak etkileşime girmesi için gereken yaygın güvenin, kısmen bu ülkelerin demokratik kurumlarının ne kadar ayakta ve uzun sürdüğüne bağlı olduğunu göstermektedir (Curtis, Baer, Grabb, 2001, s.785).

Neoliberal gündemin bir parçası olarak hükümetler, gönüllülük vasıtasıyla vatandaşların refahına karşı sorumluluklarını azaltmakta, gönüllüler ve gönüllü kuruluşlar vasıtasıyla bu konudaki açığı doldurmakta ve devamında kamu hizmetlerinin özelleştirilmesine izin verebilmektedir. Dolay1sıyla batılı hükümetler, değişen derecelerde vurgu ile doğru bir şekilde tanımlanmış ve düzenlenmiş gönüllü çalışmanın desteklenmesi ve teşvik edilmesi gerektiğini düşünmektedirler. Liberallerin ve muhafazakârların konuyu nasıl değerlendirdiğine bakılacak olursa, liberallere göre gönüllülük hükümetin eylemlerini desteklemenin, tamamlamanın ve hükümeti daha güçlü, kapsamlı göstermenin bir yoludur. Muhafazakârlara göre ise gönüllülük, hükümet programlarının yerine geçmekte ve hükümetin gücünü, kapsamını azaltmaktadır. Ayrıca güçlü bir gönüllü güç, demokratik olarak seçilmiş bir hükümetin gücünü en aza indirebilmekte ve özellikle elit temelli gönüllü grupların küçük gruplarına ilave söz verebilmektedir (Hustinx vd., 2010, s.420-428).

Farklı bakış açlarının temelini oluşturan idari gelenekler, vatandaş katılımını önemini devlet-toplum ilişkileri, politika tarzı ve merkeziyetçilik/adem-i merkeziyetçilik bağlamında yansıtmaktadır. Fransa, çoğu zaman bölgesel idare üzerinde merkezi kontrole sahip bir yönetim geleneğine sahip olarak kabul edilmektedir. Son zamanlardaki yerelleşme reformlarının belirginliğine rağmen, Napolyon yönetim geleneği nedeniyle Fransa'daki vatandaş katılım yöntemlerine hala az önem verildiği görülmektedir. Almanya'daki idari gelenek, federal ve korporatist bir çerçeveden kaynaklanan, "hükümetin güçlerini yöneten federal bir sistemde bölgesel ve yerel 
seviyelerde güçlü bir ulusal demokrasi geleneği" olan organikçi bir yapı olarak nitelendirilmektedir. Üçüncü sektör, pazar ve sivil toplum grupları, devletin federal, bölgesel ve yerel düzeylerde çıkar dernekleriyle işbirliği yaptığı "bütünleştirici" bir politika modelini teşvik eden devlet işlevlerine sahiptir. Çok düzeyli yönetişim süreçleri, bölgesel ve yerel özerkliği teşvik etmekte ve "işbirlikçi federalizm" vatandaşların katılımı için çeşitli mekanizmalar sağlamaktadır. Vatandaş girişimleri, referandumlar ve yerel yönetim düzenlemeleri için anayasal haklar, karar alma sürecine doğrudan katılım sağlarken, yerel düzeyde; konsey komiteleri, vatandaş forumları, panelleri ve toplulukları aracilığıla katılım sağlanmaktadır. İngiltere, çoğulcu bir geleneğe sahip olmakla birlikte, merkezi yönetim genellikle ulusal yönetim faaliyetlerinde önemli bir kontrol sağlamaktadır. Vatandaş katılımı yerel düzeyde önemlidir ve bu katılım, politika geliştirilmesinden ziyade hizmetlerin sağlanmasına odaklanmaktadır. Vatandaş katılımı yerel yönetişim üzerinde olumlu etkiye sahip olmakla birlikte, gerçekte yerel yönetimlerin düşük takdir yetkisine sahip olduğu, makul/orta seviye işlevleriyle birlikte aslında merkezi politika oluşturmada zayıf kaldıkları düşünülmektedir. İskandinav modeline vurgu ile Norveç; sınırlı yerel yönetimler, güçlü merkeziyetçilik ve zayıf bölgesel yapılar ile Sakson modeline uyarken, ortak fikir birliğine yönelim ve neo-korporatist kolektif karar alma yaklaşımı ile organikçi modelin öğelerini yansıtmaktadır. Denetimin merkeziyetçiliği ve istikrar/tekdüzelik ile Napolyon modelini de barındıran bu yapıdaki kolektivist, eşitlikçi ve güçlü demokratik gelenek ve kamu görevlilerine ve topluma duyulan güven, vatandaş katılımının yüksek olacağına işaret etmektedir (Huxley, Andrews, Downe ve Guarneros-Meza, 2016, s. 7-12).

Gönüllülük her ne kadar farklı kavramlarla ifade edilse veya ülkeler tarafından farklı şekillerde uygulansa da gönüllü katılım 1980'lerden sonra yönetim anlayışında görülen değişim neticesinde devletin etkinleştirilmesi, yerelde ise hizmetlerin katılımcı demokrasi temelinde vatandaş etkileşimiyle daha etkin görülmesi amacıyla kullanılan bir yöntem olarak dikkat çekmektedir. Bu süreçte bireylerin uygun programlar çerçevesinde hizmetlerin görülmesine ve toplumsal kalkınmaya yapacakları katkı, birey-toplum işbirliği ortamında demokrasinin de güçlenmesini sağlayacaktır ( Palabıyık, 2011,s. 90). 


\section{Türkiye'de Gönüllü Katılım}

Türkiye'de gönüllü katılım çok da aşina olunmayan bir durumdur. Çünkü sivil toplum mantığı ve hareketi son dönemde gelişmekle birlikte, hâlâ sadece küçük bir gruba hitap eder nitelikte ve vatandaşların büyük bölümünden kopuk bir şekildedir. Halkın \%4,5'i sosyal, \%5,3'ü siyasi nitelikte bir sivil toplum kuruluşuna üyedir ve $\% 2,5^{\prime}$ i sosyal, $\% 4,2^{\prime}$ si siyasi nitelikte bir sivil toplum kuruluşunda gönüllü faaliyette bulunmaktadır. Türkiye'de sivil topluma halkın sadece küçük bir kesiminin katılmasına rağmen, sosyal nitelikteki bir STK'ya üye olan vatandaşların $\% 11,5$ 'i, gönüllülük yapanların ise \% 30'u en az bir diğer STK'ya daha üyedir veya gönüllü destek vermektedir. STK etkinliklerinde sosyalleşenlerin ise $\% 81,9^{\prime} \mathrm{u}$, bu faaliyetlere sik sik katılmaktadır. Benzer şekilde siyasi nitelikteki bir STK'ya üye olan vatandaşların \%16,7'si, gönüllülük yapanların ise \% 21,6'sı, en az bir diğer STK'ya daha üyedir veya gönüllü destek vermektedir. Farklı sosyal grupların (25 yaş altı gençlik, 65 yaş üzeri yaşlılar, kadınlar, etnik azınlıklar ve alt sınıf) katılım eğilimleri incelendiğinde ise bu gruplardan neredeyse hiçbirinin STK'larda gereken veya yüksek düzeyde bir katılım göstermediği de yapılan başka bir tespit olmaktadır (İçduygu, Meydanoğlu, Sert, 2011, s.19).

Sivil Toplum Endeksi'ne (CSI) göre ise nüfusun \% 10'undan azı düzenli olarak yılda en az bir kez gönüllü çalışmakta ve ortalama olarak ayda gönüllü çalışmaya 5,1-8 saat ayırmaktadır. Benzer şekilde, Yardım Kuruluşları Vakfı (CAF) tarafından hazırlanan 2014 Dünya Bağış Endeksi'ne göre Türkiye'de nüfusun sadece \% 5'i gönüllü olarak faaliyette bulunmakta, \% 12'si bir sivil toplum kuruluşuna bağış yapmakta ve \% 38'i ihtiyacı olan bir yabanciya yardım etmektedir. Araştırmadaki bu rakamlar, Türkiye'yi 153 ülke arasında 128. sırada göstermektedir (Akboğa, 2017, s.248).

Türkiye'de gönüllü kuruluşlara katılma konusundaki coşku eksikliği, kısmen kişilerarası güvensizlik duygusunun derinden nüfuz ettiği bir kültürden kaynaklanıyor gözükmektedir ve oy veren kesim için insanlar güvenilmezdir. Dünya Değerler Araştırması'na göre Türkiye' de kişiler arası güven seviyesi oldukça düşüktür. Her ne kadar bu güven eksikliği ekonomik, politik ve kültürel olsa da ortaklıklar veya işbirliği kurma çabalarını da olumsuz etkilemektedir. Zira farklılıklara karşı hoşgörüsüzlük, gönüllü kuruluşların aynı ve birkaç üyeyle hareket etmesine neden olmaktadır. Bu nedenle gönüllü kuruluşların aktif katılımcıları, devletle etkileşim halinde- 
dir. Çünkü katılımcıların etkinliği, politik kaynaklar üzerindeki etkinliğine, işbirliği kapasitesine ve devletle ilişkili olan diğer örgütlerle işbirliğine bağlıdır. Bu ilişkiler ağında gönüllü kuruluşlar devleti bir rakip olarak görmemekte, rakiplerine karşı beraber hareket edebilecekleri bir müttefik olarak değerlendirmektedirler (Kalaycıoğlu, 2002, s.257). Bu nitelikteki birçok kuruluş, aslında olması gerektiği şekliyle bireylerin taleplerini devlete ileterek karar alınmasını sağlamaktan ziyade, devletin talep ve ideolojik tercihlerini topluma taşımaktadır (Aslan, 2010, s.261, 280). Bu mantık ise Türkiye'de gönüllülük kavramına yaklaşım açısından akıllarda soru işareti uyandırmaktadır.

Türkiye'deki sivil toplum kuruluşlarının veya gönüllü kuruluşların durumu ulusal ve uluslararası araştırmalar noktasında bu şekilde kısaca verildikten sonra bahsedilmesi gereken başka bir husus, gönüllülük tanımının nasıl yapıldığ 1 ve buna ilişkin politikaların nasıl yürütüldügü konusudur. Gönüllülüğe ilişkin net ve tek bir tanım olmamakla birlikte, Türkiye'de gönüllülük politikaların belirleyen bir kamu kurumu da bulunmamaktadır. Sivil toplum kuruluşları "genellikle kendi hedeflerine ve misyonlarına dayanarak oluşturdukları, yazılı olmayan ifadelerine dayanarak gönüllülük politikaları oluşturmakta ve gönüllü faaliyetlerini buna göre yapmaktadırlar" (Akboğa, 2017,s.251). Fakat hangi profildeki insanlar, nasıl katılım sürecini gerçekleştiriyorlar sorusuna cevap verebilecek araştırmalardan biri olarak 2014 yılında yapılan Şebeke araştırması, gençlerin \% 9'unun siyasi partilerden birine üye olduğunu ve partide veya gençlik kollarında aktif rol ald1ğını, gençlerin büyük çoğunluğunun ise siyasi partilere üye olmak istemediğini ortaya koymuştur. Parti üyeliğine çok sıcak bakılmasa da gençlerin \%27'si bir STK'ya veya üniversite kulübüne üye oldukların belirtmişlerdir. Herhangi bir STK'ya üye olmayanlar ise mazeret olarak zamanlarının olmamasını sunmuşlardır. Ayrıca araştırmada aileleriyle birlikte yaşamayan gençlerin daha fazla gönüllü olduğu ortaya çıkmıştır. TEGV Araştırmasına göre ise gelir seviyesi arttıkça gönüllülük azalmakta ve bu insanlar bu duruma neden olarak zamanlarının olmamasını göstermektedir. Genel bir değerlendirme yapıldığında ise Türkiye'de insanlar gönüllü olarak ya da hayırseverlikle uğraşırken, bunu çoğunlukla dini yükümlülüklerin bir parçası olarak yapmaktadır. Bu durumun dışında, yapılması gerektiğini düşündüğü faaliyetleri devletin yerine getirmesini istemektedir (Akboğa, 2017, s.256). 
Farklı araştırmalar ve sonuçlar olmakla birlikte, 2005 tarihli İl Özel İdaresi ve Belediye Hizmetlerine Gönüllü Katılım Yönetmeliği, gönüllüyü;; "bilgi, beceri ve yeteneğini, her türlü ortak çalışma, imkân ve zamanını ortaya koyarak çalışma alanı konusunda maddi bir kazanç beklemeksizin yerel yönetim hizmetlerine katılan gerçek ve tüzel kişiler ile bünyesindeki gönüllüleri bu hizmetlerde görevlendirecek kamu kuruluşları" olarak ifade etmiştir(m.4). Il özel idaresi ve belediye hizmetlerinin yürütülmesindehemşehrilerin gönüllü katılımına ilişkin usul ve esasları düzenlemek (m.1) amacıyla çıarılan yönetmelik; sağlık, eğitim, spor, çevre, park, trafik, itfaiye, kütüphane, kültür, turizm ve sosyal hizmetlerle; yaşlılara, kadınlara, gençlere, çocuklara, özürlülere, yoksul ve düşkünlere yönelik hizmetlere gönüllü katılıma ilişkin hususları kapsamaktadır (m.2). Yine ilgili yönetmelikte, gönüllü olabilmek için gereken şartlar sıralanmış (m.7), il özel idaresi veya belediye görev ve sorumluluklarına bağlı olarak yetki alanlarında; “a) Özürlülere, çocuklara, kadınlara, gençlere, yaşlılara, yoksullara, kimsesizlere ve düşkünlere yönelik eğitim, kültür, sağlık ve sosyal hizmetleri, b) Kütüphane, tiyatro, sinema gibi kültür hizmetleri, c) Bilişim, meslek edindirme kursları, kreş gibi eğitim hizmetleri, d) Park, bahçe, kent estetiği, çevre düzenlemeleri ile katı atık gibi çevre kirlenmesinin önlenmesine yönelik hizmetleri, e) Başıboş ve sahipsiz hayvanlara yönelik hizmetleri, f) Trafik, itfaiye, arama-kurtarma gibi denetim ve acil yardım hizmetleri, g) Tüm yaş gruplarını içine alan her türlü spor hizmetleri, h) Tarihi, kültürel mirasın ve tabiat varlıklarının yaşatılarak korunması hizmetleri yapmak üzere gönüllü çalıştırabilir (m.5)" hükmü yer almıştır.

Türk kamu yönetimindeki genel eğilimin bir yansıması şeklinde, gönüllülük konusunda da kısa resmi bir metin olmakla birlikte, uygulanabilirliğinin nasıl daha iyi sağlanabileceği konusunda herhangi bir resmi çalışma göze çarpmamaktadır. Ancak her şeyden öte hemfikir olunabilecek yegâne konu, Türkiye'de özel ve tüzel nitelikte, genel olarak sivil toplum mantı̆̆gnın yerleştirilmesi ve asıl amacını gerçekleştirecek sivil toplum kuruluşlarına ihtiyaç duyulduğudur.

\section{Sonuç}

Sosyal, ekonomik ve kültürel bir olgu olarak bireyler, gruplar ve örgütler arasındaki etkileşimi değerlendiren ve karşıllksız bir şekilde gerçekleştirilen 
gönüllülük; fedakarlık, merhamet, endişe veya cömertlik gibi insani ve subjektif değerlerle ifade edilmektedir. Subjektif bir değerlendirme yanında kimin gönüllü olduğu ve hangi faaliyetlerin gönüllülük kapsamında değerlendirileceği ise içinde bulunulan durum itibariyle anlamsal olarak farkl1laşmaktadır. Bu farklılığın temelinde ise bu kavrama ilişkin bir halk algısı meselesinin yattığı düşünülmektedir. Zira hangi toplum, hangi faaliyeti gönüllülük kapsamında değerlendiriyor, devletin bu konudaki rolü nedir, gelenekler bu süreç veya yapıyı nasıl etkiliyor, sivil toplum kuruluşları bu çerçevede nasıl faaliyette bulunuyor veya katılımcllık ne ifade ediyor gibi sorular aslında bu kavramın şekil almasında önemli faktörler olmaktadır.

Sadece sağladığı fayda açısından değil aynı zamanda maliyetleri paylaşma açısından gerçekleştirilen ve resmi bir şekilde de desteklenen gönüllü faaliyetler, bireysel özellikler anlamında kimler tarafından gerçekleştiriliyor sorusuna cevap bulmak amacıyla gerçekleştirilen araştırmalarda çok farklı sonuçlarla analiz edilmiştir. Genel anlamda orta yaş gönüllülük için uygun görülürken değişen şartlara bağlı olarak ergenlik dönemindeki gönüllü̈lük faaliyetlerinin ileriki zamanlardaki gönüllü faaliyetler için daha uygun olduğu sonucuna da varılmıştır. Amerika'da kadınlar daha fazla gönüllü faaliyette bulunurken Avrupa'da erkekler daha gönüllü olmakta hatta İsveç'te tamamen erkek egemen bir şekilde yürütülmektedir. Ekonomik durumu iyi olanların daha gönüllü olması beklenirken aslında ekonomik durumları iyi olmayan toplumların birbirlerini destekleme anlamında gayri resmi bir şekilde daha fazla gönüllü ilişkiler kurduğu görülmüştür. Bu örneklerin arttırılması söz konusu olmakla birlikte din açısından yapılan analizler burada kilit noktayı oluşturmaktadır. Bir dine, dini kuruma ve mezhebe bağlı bir şekilde, katılım ve üyelik arasındaki anlamsal ince çizgi korunarak yapılan gönüllülük faaliyetlerinin ağsal ilişkiler anlamında bir geçiş sağladığ1 düşünülmüştür. Bu konuda da tek bir yargıya ulaşılamamış, mesela Protestanların gönüllü faaliyetlere katılımın daha fazla olması beklenirken Katolik olup daha fazla gönüllü faaliyet yürüten ülke ve toplumlarla karşılaşılmıştır.

Bu farklılıklarla birlikte sivil toplum kuruluşları vasıtasıyla katılım mekanizmasının daha etkin hale getirilmesinin, vatandaşların yönetim ve karar alma sürecinde daha aktif rol almasını sağlayacağı beklenmektedir. Demokrasinin bir unsuru olarak görülen katılım kavramının gönüllülük vasıtasıyla vatandaşların taleplerini daha dikkate alır şekilde yerine getirilmesine aracl- 
lık etmesi, devletin üzerindeki yükün/maliyetin bir kısmını almakta, hizmet etkinliğini artırmakta ve toplumsal yapıyı laboratuar bir deneyden öteye taşımaktadır. Bu amaçla temsili demokrasiden katılımcı demokrasiye geçiş yaşanması gerektiği düşüncesiyle katılımın, vatandaş bazında farkındalığın ve bunun pozitif etkisi ile hizmetlerin kalitesinin artması beklenmekte, siyasi ve yönetsel açıdan katılım mekanizmaları hem artırılmakta hem de daha uygulanabilir kılınmaya çalışılmaktadır. Ancak kabul edilen bu doğrular yanında ülkelerin dahil olduğu yönetsel kültür tipi, katılımın dolayısıyla gönüllülüğün içeriğini değiştirmektedir.

Türkiye'de ise gönüllü katılım konusunda rehberlik edecek resmi kurumsal bir düzen veya yerleşik bir anlayış olmamakla birlikte, zayıf ve devlete yakınlığıyla kendini ifade edebilen sivil toplum kuruluşlarının her biri gönüllülük sürecine kendi faaliyetleri doğrultusunda yön vermektedir. Gönüllü katılıma bir adım daha yaklaşılmasını sağlayacak olan katılım, farklı araçlarla daha etkin bir şekilde sağlanmaya çalışılırken maalesef kağıt üstünde kendine yer bulan 2005 tarihli "İl Özel İdaresi ve Belediye Hizmetlerine Gönüllü Katılım Yönetmeliği”" yerel düzeyde gönüllü faaliyetlerin nasıl ve kimler tarafından yürütüleceğine kısa cevaplar vermektedir. 
EXTENDED ABSTRACT

\title{
The Relationship between Volunteering, Participation and Administration Culture
}

\author{
Vasfiye Çelik \\ Kırkkkale University
}

While acting within the framework of formal and informal relations in order to realize the benefit of the public generally and the target audience basically, without expecting any response, is explained with the concept of volunteerism, this concept is firstly expressed in the mind with humane and subjective values such as sacrifice, compassion or generosity. Alexis de Tocqueville's work on "Democracy in America" on which groups carry out voluntary action in social life academically increased the interest in this issue. In addition to a subjective evaluation, it is thought that the issue of public perception regarding this concept lies behind it, while there are differences in terms of meaning on who volunteers are and which activities are to be evaluated within the scope of volunteering due to the situation in which are. Yet, questions such as which society evaluates which activity within the scope of volunteering, what is the role of the state in this matter, how traditions affect this process or structure, how civil society organizations operate in this framework or what does participation mean, are actually important factors in shaping this concept.

The concept of volunteering, evaluated in various ways due to different personal characteristics in social life, is analyzed differently depending on the variables such as age, gender, religion or sect, marital and economic situation based on profile. Voluntary activities carried out not only in terms of benefits but also in terms of sharing costs and supported in an official way are analyzed with very different results in the researches made in order to answer the question of who executes in terms of individual characteristics. While middle age is considered suitable for volunteering in general terms, it is concluded that volunteering activities in adolescence period are more suitable for volunteer activities in the future. While women are more voluntary in the US, men are more voluntary in Europe and even in Sweden, it is conducted in a completely male-dominated manner. While 
those with good economic conditions are expected to be more voluntary, it is also observed that societies with inadequate economic conditions establish informally more voluntary relationships in terms of supporting each other. Although these examples are to be increased, the analyzes made in terms of religion constitute the key point here. Namely, it is thought that volunteering activities carried out by preserving the semantic fine line between participation and membership, depending on a religion, religious institution and sect, provide a transition in terms of network relations. While it is observed that those considered religious are more engaged and voluntary, it is claimed that sectarian difference is also important in this regard. However, a single judgment could not be reached on this matter. For example, while Protestants are expected to have more participation in voluntary activities, we see that there are Catholic and more volunteer countries and communities. When an evaluation is in general terms made, it is seen that the researches on this subject differ rather than reaching a single result.

Under the study, participation, another concept to be analyzed in the context of the subject of the study and to analyze the relationships between volunteering and participation, is seen as an essential element of democracy. The fact that the concept of participation mediates the fulfillment of the demands of the citizens through volunteering takes some of the burden/cost on the state, increases service efficiency, and takes the social structure beyond a laboratory experiment. For this purpose, with the thought that there should be a transition from representative democracy to participatory democracy; it is expected that participation, awareness on the basis of citizens, and the quality of the services with the positive effect of this increase, and within this framework, political and administrative participation mechanisms are tried to be increased and made more feasible. In this regard, while participation comes to the fore, the fact that citizens have an impact on the provision of services instead of waiting for everything from the state brings together the concepts of volunteer and participation. However, this case of being side-by-side requires a strong civil society, and it is another issue to be noted that not every society has this development and necessary institutional structure.

In addition to these accepted truths, the type of administrative culture in which countries are involved changes the content of participation, therefore, 
volunteering. The shared common ground is considered that the services provided are better accomplished and the citizens participate in the managerial process. Voluntary participation is influenced by many variables in different management cultures, basically refers to spiritual values, and accepted that it is tried to be achieved by supported by the state for different reasons. However, on the practical side of these core values, it is important to note that the development of civil society thought and the different administrative traditions or managerial cultures add the difference to the concept and the content.

When looked at the subject in terms of Turkey; the lack of a clear definition of voluntary, the absence of the expected development in the civil society thought, and the being of participation only in official texts briefly explain the relationship of voluntary-participation-management culture. In Turkey, which is considered within the Continental European managerial culture and performs its public administration organization with such basic facts as rule of law, bureaucracy, and indivisible integrity of the state, volunteering is usually carried out by a religious point of view. The general thought regarded the participation as a companion of volunteering in the world is that the civil society organizations need to become strong for participation to be more visible, this phenomenon and the practices related to it are weak because the civil society organizations in Turkey are not very effective. Because the public opinion in Turkey is covered with that the state dominates every area and does everything rather than citizens carry out some processes. The purpose of this study provides guidance on the variables in empirical studies of international literature via country samples, in terms of managerial cultural difference in the studies on voluntary participation in the future, in Turkey in which the participation paths are not used in very effective under the acceptance that civil society is inadequate.

\section{Kaynakça / References}

Akboğa, S. (2017). The current state of volunteering in Turkey. Jacqueline Butcher\&Christopher J. Einholf (Der.), Perspectives on Volunteering içinde (s.245-261). Switzerland, Springer.

Anheiner, H.K., Salamon, L.M. (1999). Volunteering in cross-national perspective: Initial comparisons. Law And Contemporary Problems , 62(4), 43-65. 
Arnstein, S.,R. (1969). A ladder of citizen participation. Journal of the American Institute of Planners, 35(4), 216-224.

Aslan, S. (2010).Türkiye'de sivil toplum. Elektronik Sosyal Bilimler Dergisi, 9(31), 260-283. 11 Aralık $2019 \quad$ tarihinde https://dergipark.org.tr/tr/download/article-file/70174 adresinden erişildi.

Bachmann, P.L., Delgado,L.E. ve Marin, V.H. (2007). Analysis of the citizen's participation concept used by local decision makers: The case of the Aysén watershed in Southern Chile. Int. J. Sustainable Development, 10(3), 251-266.

Bogner, A. (2012).The paradox of participation experiments. Science, Technology, $\mathcal{E}$ Human Values, 37(5), 506-527.

Boje, T., P. (2015). Organized civil society, volunteering and citizenship. Enjolras B.\& Karl S. (Der.), Civil Society in Comparative Perspective içinde (s.243262). Bingley: Emerald.

Brudney, J.L. (1993). Volunteer involvement in the delivery of public services: Advantages and disadvantages. Public Productivity \& Management Review, 16 (3), 283-297.

Cicognani, E., Pirini, C., Keyes, C., Joshanloo, M. ve Rostami, R. (2008). Social participation, sense of community and social well being: A study on American, Italian and Iranian university students. Social Indicators Research, 89(1) ,97-112.

Curtis, J.E., Grabb, E.G. ve Baer, D.E. (1992). Voluntary association membership in fifteen countries: A comparative analysis. American Sociological Review, 57, 139-152.

Curtis, J.E., Baer, D.E. ve Grabb, E.G. (2001). Nations of joiners: Explaining voluntary association membership in democratic societies. American Sociological Review, 66(6), 783-805.

Dekker, P., Van Den Broek, A. (1998). Civil society in comparative perspective: Involvement in voluntary associations in North America and Western Europe. International Journal of Voluntary and Nonprofit Organizations, 9(1), 11-38.

Erlinghagen, M., Hank, K. (2005). Participation of older europeans in volunteer work. MEA discussion papers, Mannheim, University of Mannheim

Grant, A.M. (2012). Giving time, time after time: Work design and sustained employee participation in corporate volunteering. The Academy of $M a-$ nagement Review, 37(4), 589-615. 
Hackl, F., Halla, M. ve Pruckner, G. J. (2012). Volunteering and the State. Public Choice, 151(3-4), 465-495.

Hansen, H., S., Reinau, K., H. (2006). Who are the citizens in public participation GIS. Proceedings 25th Urban Data Management Symposium.Aallborg,14, 25-36.

Higgs, G., Berry, R., Kidner, D. ve Langford, M. (2008). Using IT approaches to promote public participation in renewable energy planning: Prospects and challenges. Land use policy, 25(4). 596-607.

Hustinx, L., Cnaan, R.A. ve Handy, F. (2010). Navigating theories of volunteering: A hybrid map for a complex phenomenon. Journal for the Theory of Social Behaviour, 40(4), 410-434.

Huxley, K., Andrews, R. W., Downe, J. ve Guarneros-Meza, V. (2016). Administrative traditions and citizen participation in public policy: A comparative study of France, Germany, the UK and Norway. Aralik 2019 tarihinde http://orca.cf.ac.uk/72834/ adresinden erişildi.

İçduygu, A., Meydanoğlu, Z. ve Sert, D.Ş (2011). Türkiye'de sivil toplum: Bir dönüm noktası. TÜSEV Yayınları, 51, 1-191

Janoski, T., Musick, M. ve Wilson, J. (1998). Being volunteered? The impact of social participation and pro-social attitudes on volunteering!. Sociological Forum,13(3), 495-519.

Kalaycioğlu, E. (2002). State and civil society in Turkey: Democracy, development and protest. A.B. Sajoo (Der). Civil society in the Muslim world: Contemporary perspectives içinde (s. 247-272). London, I.B. Tauris.

Kestellioğlu, G. (2011).Yerel demokrasi ve kent konseyleri: Kahramanmaraş örneği. Kahramanmaraş Sütçü Imam Üniversitesi İktisadi ve İdari Bilimler Fakültesi Dergisi, 1(1), 121-140.

Keyman, F. (2004). Avrupa'da ve Türkiye'de sivil toplum. Sivil Toplum Geliştirme Merkezi STK Kapasite Geliştirme Ĕ̆itim Programı Ders Notları, 23, 1-14.

Knill, C. (1998). Implementing European policies: The impact of national administrative traditions. Journal of Public Policy, 18(1), 1-28.

Lam, P-Y. (2002).As the flocks gather: How religion affects voluntary association participation. Journal for the Scientific Study of Religion, 41(3), 405-422.

Lee, Y-P., ve Brudney, J.,L. (2012). Participation in formal and informal volunteering implications for volunteer recruitment. Nonprofit Management ELeadership, 23(2), 159-180.

Loughlin, J., Peters, G. (1997). State traditions, administrative reform and regionalization. M. Keating, J. Loughlin (Der), The Political Economy of Regionalism içinde (s. 41-62). Routledge 
Mcallum, K. (2017). Volunteers/volunteering. The International Encyclopedia of Organizational Communication, 2-14.

Önder, Ö. (2013). Yerelleşme ve yerel demokrasinin güçlendirilmesi bağlamında yerel katılım. Uluslararası Yönetim İktisat ve İşletme Dergisi, 9(18), 311-326.

Palabıyık, H. (2011). Gönüllülük ve Yerel hizmetlere gönüllü katılım üzerine açıklamalar. Yönetim Bilimleri Dergisi, 9(1), 86-114

Peters, B.G. (2008). The napoleonic tradition. International Journal of Public Sector Management, 21(2), 118-132.

Rhodes, R.A.W. (1999). Traditions and public sector reform: Comparing Britain and Denmark. Scandinavian Political Studies, 22(4), 341-370.

Ruiter, S., De Graaf, N.D. (2006).National context, religiosity, and volunteering: Results from 53 countries. American Sociological Review, 71, 191-210.

Şebeke Araştırması (2014). İstanbul Bilgi Üniversitesi Yayınları 457, Birinci Baskı Van Deth, J.,W. (2001). Studying political participation:Towards a theory of everything?. Workshop Electronic Democracy: Mobilisation, Organisation and Participation via new ICTs", Grenoble

Van Deth, J.W. (2014). A conceptual map of political participation. Acta Politica, 49(3), 349-367.

Wilson, J. (2000).Volunteering. Annual Review of Sociology, 26(1),215-240

Yalçın, A. Z. (2015). Yerel yönetimlerde katılımcı bütçeleme. Yönetim ve Ekonomi, 22(2), 311-329.

2005 Tarihli İl Özel İdaresi ve Belediye Hizmetlerine Gönüllü Katılım Yönetmeliği, $\quad 12.11 . \quad 2019 \quad$ tarihinde https://www.mevzuat.gov.tr/Metin.Aspx?MevzuatKod=7.5.9521\&Mevz uatlliski=0\&sourceXmlSearch=il $\% 20 \%$ C3\%B6zel adresinden erişilmiştir.

\section{Kaynakça Bilgisi / Citation Information}

Çelik, V. (2020). Gönüllülük, katılım ve yönetim kültürü ilişkisi. OPUSUluslararası Toplum Araştırmaları Dergisi, 15(25), 3819-3850. DOI: 10.26466/opus.658674 